\title{
Suhaiza Salleh · Ian Arthur \\ Persistent peritoneal trophoblastic implantation following salpingotomy, salpingectomy, and methotrexate for ectopic pregnancy
}

Received: 6 February 2005/ Accepted: 15 March 2005 / Published online: 21 May 2005

(C) Springer-Verlag Berlin / Heidelberg 2005

\begin{abstract}
A well recognized complication of conservative surgical treatment for tubal ectopic pregnancy, salpingotomy, is incomplete removal of trophoblastic tissue. Secondary trophoblastic implantation needs to be considered especially in cases of persistent disease following salpingectomy. We report an unusual and rare case of persistent peritoneal trophoblastic implantation following salpingotomy, salpingectomy and methotrexate for tubal ectopic pregnancy. This case illustrates that the treatment of ectopic pregnancy can prove to be difficult, even if the initial diagnosis is "obvious". It shows that persistent trophoblastic disease can occur not only after salpingotomy but also after salpingectomy and methotrexate, hence the need for postoperative serum beta human chorionic gonadotrophin (Bhcg) in all cases. It also demonstrates that secondary implantation is a possibility in persistent disease and thorough examination of the pelvis, the peritoneal and serosal surfaces is mandatory.
\end{abstract}

Keywords Persistent trophoblast - Salphingotomy · Salphingectomy $\cdot$ Methotrexate $\cdot$ Laparotomy $\cdot$

Peritoneal Implantation

\section{Case report}

A 33-year-old woman, gravida 2, para 1, presented at 6 weeks' gestation with a 1-day history of right iliac fossa pain and light vaginal bleeding. It was a planned and very much wanted pregnancy. Ultrasound exami-

\footnotetext{
S. Salleh $(\bowtie)$

Department of Obstetrics and Gynaecology,

Wythenshuwe Hospital, Southmoor Lane,

Wythenshuwe, Manchester, M23 9LT, UK

E-mail: suesalleh@hotmail.com

Tel.: + 44-73-2543927

I. Arthur

Blackpool, UK
}

nation showed an empty uterus. In the left adnexa, between the uterus and the left ovary, there was a gestational sac with a yolk sac present, an appearance suggestive of a left tubal ectopic pregnancy. The woman was asymptomatic and haemodynamically stable, and a laparoscopic procedure was arranged.

At laparoscopy, a $2 \times 2-\mathrm{cm}$ left isthmic unruptured ectopic pregnancy was seen. The fimbrial end of the right fallopian tube was not seen, as it was abnormally "tucked" behind the right ovary. In view of the possibility of a contralateral unhealthy fallopian tube and the patient's desire for future fertility, a left salpingotomy was performed. The histology from the product removed from the left fallopian tube confirmed an ectopic pregnancy.

Postoperative surveillance of serum beta human chorionic gonadotrophin (Bhcg) showed high and rising levels (see Table 1). An ultrasound scan was arranged on the 15th postoperative day, which showed thin endometrium with no evidence of pelvic mass.

A second laparoscopy was performed 19 days after the first one. The left fallopian tube was noted to be opened from previous surgery and adherent to the back of the uterus. A left salpingectomy was performed, and the histology confirmed the presence of trophoblastic villi. Laparoscopic examination revealed a partially organised haematoma at the base of the appendix. This was removed, but the histology revealed no evidence of fetal parts or trophoblastic villi.

The patient presented 5 days after the salpingectomy (25 days after the salpingotomy) with abdominal pain. She was haemodynamically stable, and there were no abdominal signs. Serial serum Bhcg showed high and rising levels (see Table 1).

The treatment options of laparotomy or methotrexate injection were discussed with the patient, and she chose the medical option. An injection of methotrexate at the dose of $1 \mathrm{mg} / \mathrm{kg}$ was given intramuscularly 8 days after the salpingectomy ( 27 days after the salpingotomy). Although the serum Bhcg level dropped following the injection, it started to rise again. The patient 
Table 1 Intervention and postoperative serum beta human chorionic gonadotrophin (Bhcg) levels

\begin{tabular}{|c|c|c|}
\hline & Intervention & $\begin{array}{l}\text { Serum Bhcg } \\
\text { levels (IU/1) }\end{array}$ \\
\hline Day 0 & Laparoscopic left salpingotomy & \\
\hline Day 7 & & 1,400 \\
\hline Day 14 & & 5,100 \\
\hline Day 15 & & 6,500 \\
\hline Day 17 & & 6,800 \\
\hline Day 19 & Laparoscopic left salpingectomy & \\
\hline Day 25 & & 9,300 \\
\hline Day 26 & & 11,000 \\
\hline Day 27 & Methotrexate $1 \mathrm{mg} / \mathrm{kg}$ intramuscularl & \\
\hline Day 29 & & 7,300 \\
\hline Day 32 & & 8,100 \\
\hline Day 34 & $\begin{array}{l}\text { Evacuation of uterus, laparotomy, } \\
\text { peritoneal trophoblastic implants }\end{array}$ & excision of \\
\hline Day 35 & & 3,500 \\
\hline Day 39 & & 1,500 \\
\hline Day 43 & & 330 \\
\hline Day 53 & & 160 \\
\hline Day 61 & & 73 \\
\hline Day 67 & & 22 \\
\hline
\end{tabular}

continued to have abdominal pain, and a laparotomy was agreed upon.

Surgical evacuation of the uterus and laparotomy were performed 7 days after the methotrexate injection ( 15 days after the salpingectomy; 34 days after the salpingotomy). The uterus was empty. At laparotomy, deposits of possible trophoblastic tissue were noted on the posterior and right pelvic peritoneum. These lesions were excised, and the histology showed evidence of trophoblastic tissue and choronic villi in these implants. Serial serum Bhcg declined slowly postoperatively (see Table 1).

\section{Discussion}

Tubal ectopic pregnancy can be managed surgically, medically, or, in certain selected cases, by observation alone. The chosen management would depend on the individual case, taking into consideration the woman's clinical condition and her future fertility requirement.

In a haemodynamically stable patient, the laparoscopic approach is preferable to a laparotomy. Results from a prospective trial showed that the subsequent intrauterine pregnancy rate was similar; laparoscopically-treated patients had a significant reduction in estimated intraoperative blood loss, postoperative hospital stay, narcotic requirements, time to normal activity, and total hospital costs [5].

In women with contralateral tubal disease, conservative surgery, i.e. salpingotomy, is preferable to salpingectomy in preserving fertility. A retrospective cohort study showed that salpingotomy was associated with a higher rate of subsequent intrauterine pregnancy; it was not associated with an increased risk of repeat ectopic pregnancy, but it was associated with a significant risk of persistent trophoblastic disease [1].

A well-recognised complication of salpingotomy is incomplete removal of trophoblastic tissue; the incidence of persistent trophoblastic disease after salpingotomy has been reported to be $8 \%$ [1]. The use of a single prophylactic dose of systemic methotrexate administered postoperatively has been shown to significantly reduce the incidence of persistent trophoblastic disease from $14.5 \%$ to $1.9 \%$ [3]. It has also been demonstrated that the efficacy of methotrexate in treating persistent trophoblastic disease was reduced when Bhcg levels exceeded 5,000 IU/1 [6].

Secondary trophoblastic implantation needs to be considered, especially in cases of persistent disease following salpingectomy. The incidence of persistent trophoblastic implantation on the pelvic serosal or omental surface has been reported to be $1.9 \%$ after laparoscopy and $0.6 \%$ after laparotomy. It has been recommended that serum Bhcg be monitored postoperatively in all cases, even in patients managed by salpingectomy [2]. Clearance curves of serum Bhcg for the diagnosis of persistent trophoblastic disease have been described [4].

This case illustrates that treating ectopic pregnancy can be difficult, even if the initial diagnosis is "obvious." It shows that persistent trophoblastic disease can occur not only after salpingotomy but also after salpingectomy and methotrexate, hence the need for postoperative serum Bhcg levels in all cases. It also demonstrates that secondary implantation is a possibility in persistent disease and that thorough examination of the pelvis and the peritoneal and serosal surfaces is mandatory. This can be difficult at the time of laparoscopy even when markedly elevated Bhcg levels were recorded.

\section{References}

1. Bangsgaard N, Lund CO, Ottesen B, Nilas L (2003) Improved fertility following conservative surgical treatment of ectopic pregnancy. BJOG 110(8):765-770

2. Cartwright PS (1991) Peritoneal trophoblastic implants after surgical management of tubal pregnancy. J Reprod Med 36(7):523-524

3. Graczykowski JW, Mishell DR Jr (1997) Methotrexate prophylaxis for persistent ectopic pregnancy after conservative treatment by salpingotomy. Obstet Gynecol 89(1):118-122

4. Hajenius PJ, Mol BW, Ankum WM, van der Veen F, Bossuyt PM, Lammes FB (1995) Hum Reprod 10(3):683-687

5. Murphy AA, Nager CW, Wujek JJ, Kettel LM, Torp VA, Chin HG (1992) Operative laparoscopy versus laparotomy for the management of ectopic pregnancy: a prospective trial. Fertil Steril 57(6):1180-1185

6. Stovall TG, Ling FW (1993) Single dose methotrexate: an expanded clinical trial. Am J Obstet Gynecol 168(6 Pt 1):17591765 